\title{
Pattern of sedentary behavior in brazilian adolescents
}

\author{
Padrão do comportamento sedentário em adolescentes brasileiros
}

\section{AUTHOR'S \\ Drielly Elvira Ramos ${ }^{1}$ (iD) \\ Maria Raquel de Oliveira Bueno ${ }^{1}$ \\ Lidyane Zambrin Vignadelli ${ }^{1}$ (D) \\ André Oliveira Werneck ${ }^{1}$ (D) \\ Enio Ricardo Vaz Ronque ${ }^{1}$ (iD \\ Manoel João Coelho-E-Silva² (D) \\ Marcelo Romanzini ${ }^{1}$ (D) \\ 1 Faculty of Physical Education and \\ Sport, Londrina State University, Londrina, Brazil. \\ 2 Faculty of Sport Sciences and Physical Education, University of Coimbra, Coimbra, Portugal.}

\section{CORRESPONDING}

Marcelo Romanzini

mromanzini@uel.br

Rodovia Celso Garcia Cid, Km 380, s/n -

Campus Universitário, Londrina, Paraná,

Brazil. CEP: 86057-970.

DOI

$10.12820 /$ rbafs.23e0009

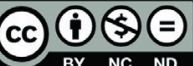

Copyright: This is an open-access article distributed

under the terms of the Creative Commons Attribution

License ${ }^{\circledR}$, which permits unrestricted use, distribution,

and reproduction in any medium, provided that the

original author and source are credited.

\begin{abstract}
The present study objectively measured the pattern of sedentary behavior among schoolchildren from a city in southern Brazil. A probabilistic sample composed of 394 adolescents was selected from ten public schools in the city of Londrina/PR. The cut-point of 720 counts. $\mathrm{min}^{-1}$ for the vector magnitude from the ActiGraph accelerometer was used to estimate the total sedentary time, bouts (1-4 $\mathrm{min}, 5-9 \mathrm{~min}, 10-14 \mathrm{~min}, 15-29 \mathrm{~min}$, and $\geq 30 \mathrm{~min}$ ), and breaks during the week, on weekdays and at weekends, as well as at school and out of school. Adolescents spent about 10 hours per day in sedentary behavior. Total sedentary time in bouts was $50 \%$ ( 278 from 535 minutes) in short bouts. Adolescents demonstrated greater time in shorter bouts $(<10$ minutes) within the school period and longer time in extended bouts ( $\geq 15$ minutes) outside school ( $p<0.05)$. Sex and socioeconomic status had no effect on sedentary time regarding bouts and number of breaks. Thus, Brazilian adolescents present high levels of sedentary time, especially during time outside school.
\end{abstract}

Keywords: Sedentary lifestyle; Epidemiology; Accelerometry.

RESUMO

O presente estudo mensurou objetivamente o padrão do comportamento sedentário em escolares de uma cidade da região sul do Brasil. Amostra probabilística composta por 394 adolescentes selecionada em dez escolas públicas da cidade de Londrina/PR. O ponto de corte de 720 counts. $\mathrm{min}^{-1}$ para o vetor magnitude do acelerômetro ActiGraph foi utilizado para estimar o tempo sedentário total, bouts (1-4 min, 5-9 min, 10-14 min, 15-29 min e $\geq 30 \mathrm{~min}$ ) e breaks ao longo da semana, durante dias de semana e de finais de semana, bem como no tempo na escola e fora da escola. Adolescentes gastaram cerca de 10 horas diárias em comportamento sedentário. Do tempo sedentário registrado em bouts, cerca de 50\% (278 de 535 minutos) foram acumulados em bouts curtos (< $10 \mathrm{~min})$. Comparativamente, adolescentes apresentaram maior tempo em bouts mais curtos ( $<10$ minutos) dentro da escola e maior tempo em bouts prolongados fora da escola ( $\geq 15$ minutos) ( $p$ $<0,05)$. Tempo sedentário, tempo em bouts e número de breaks não foram influenciados por sexo ou nivvel econômico. Em conclusão, adolescentes brasileiros apresentam elevados niveis de tempo sedentário, apresentando um padrão mais desfavorável no ambiente não escolar.

Palavras-chave: Estilo de vida sedentário; Epidemiologia; Acelerometria.

\section{Introduction}

Conceptualized as any activity performed during the time individuals spend "awake" with low energy expenditure (less than or equal to 1.5 metabolic equivalents - MET's) in the sitting or reclining position ${ }^{1}$, sedentary behavior has been characterized as an emerging risk factor for cardiometabolic diseases in children and adolescents $^{2}$. More recently, the pattern of sedentary behavior, that is, how this behavior is accumulated (volume) throughout the day or week in terms of series (bouts) and interruptions (breaks) ${ }^{3}$ has been the object of research, given its probable relationship with health outcomes in young people ${ }^{4-6}$.

Although there is still limited evidence to support this relationship ${ }^{7}$, recommendations on sedentary behavior for young people already include the need to interrupt prolonged periods of sitting as often as possible ${ }^{8}$.Thus, quantification of the pattern of sedentary behavior in children and adolescents allows better understanding of how this behavior manifests in this population group, assisting future interventionist strategies, as well as enabling monitoring of trends. In this 
sense, international surveys indicate that adolescents accumulate more than $60 \%$ of their time in sedentary activities, with about $50 \%$ of this time accumulated in bouts of short duration $(\leq 10 \mathrm{~min})^{9}$ and that this pattern tends to become more unfavorable over time ${ }^{10}$.

In Brazilian adolescents, sedentary behavior has been extensively studied ${ }^{11}$. However, the use of objective measures is still scarce. Costa et al. ${ }^{12}$ verified that Brazilian schoolchildren spend on average 64\% (132 minutes) of school time in sedentary activities, but the authors did not provide evidence on how this time was accumulated. Brazilian school children spend a significant portion of their daily time in school (about a third of the period when they are awake), an environment in which the pattern of sedentary behavior tends to manifest itself differently when compared to the period outside of school, by means of a greater number of prolonged bouts ( $>30 \mathrm{~min}$ ) and fewer breaks ${ }^{13}$. This fact may impact directly on estimates of sedentary behavior patterns on school days (weekdays) and non-school days (weekend days), although this relationship is not yet clearly evidenced in the literature $9,10,14,15$.

The present study aimed to characterize the pattern of sedentary behavior (volume, bouts, and breaks) of Brazilian adolescents over a week, on weekdays and at weekends, as well as in the school and non-school periods. Additional analyzes were also performed comparing the pattern of sedentary behavior with socio-demographic variables (sex and sociodemographic level).

\section{Methods}

The first stage of a longitudinal study on the relationship between sedentary behavior with academic performance and indicators of obesity in adolescents was carried out between September 2015 and August 2016. For this purpose, adolescents of both sexes, enrolled in the sixth (6th) year of secondary education of the public school system in the municipality of Londrina-PR were eligible for the study. The sample selection process involved two stages. Initially, two schools from each geographical region (north, south, east, west, and center) were drawn $(n=10)$ in a stratified proportional manner considering the representativeness of the school in its region. This procedure aimed to guarantee the representativeness of the geographical regions of the city in the sample. Subsequently, in the selected schools, classes were randomly selected until the percentage representation of each school in its respective region was reached. The study protocol was approved by the Ethics Committee in Research with Human Beings of the State University of Londrina according to opinion no. 1.281.324.

The data collection process involved obtaining anthropometric, sociodemographic, and accelerometry information. Measurements of body mass, height, and trunk-cephalic height were collected using standardized procedures ${ }^{16}$ with a portable digital scale (Seca, Hamburg, Germany) and a portable stadiometer with a precision of $0.1 \mathrm{~cm}$ (Harpenden Holtain Ltd, Crymych, Dyfed, UK). From this information, nutritional status was determined ${ }^{17}$. Demographic data (age and sex) and economic level ${ }^{18}$ were obtained through the application of a self-administered questionnaire. Measurements of accelerometry were obtained through the use of ActiGraph monitors (ActiGraph, Pensacola, FL, USA), models GT3X and GT3X-Plus. Both models are triaxial and use the same algorithms and filters, making subsequent comparisons between the outputs possible ${ }^{19}$. Participants were instructed to use the accelerometer for seven consecutive days during the time they were awake, with guidelines for removing equipment exclusively during bathing, water activities, and sleeping. The accelerometers were configured to collect information in epoch length of 1-second (model GT3X) or at $30 \mathrm{~Hz}$ (model GT3X-Plus).

After the monitoring period, the equipment was collected and the data stored in the ActiLife computer program (version 6.8.2). Thereafter, data were reintegrated into epoch length of 15-second. Subjects who obtained at least four valid days of data recorded by the accelerometer were included in the analyses, that is, at least eight hours of use time per day ( $\geq 480$ minutes/day), including at least one valid day of the weekend, from a criterion non-use time of 60 minutes of consecutive zeros.

The cut-off points proposed by Romanzini et al. ${ }^{20}$ for Brazilian adolescents were used to classify the counts recorded by the vector magnitude of ActiGraph in minutes of sedentary activities (180 counts. $15 \mathrm{seg}^{-1}$ ) and of moderate to vigorous physical activity (757 counts. $\left.15 \mathrm{seg}^{-1}\right)$. Bouts (sedentary series) were defined as uninterrupted periods in sedentary behavior (drop time $=0$ ) with durations of 1-4 minutes, 5-9 minutes, 10-14 minutes, 15-29 minutes, and over 30 minutes. Breaks (interruptions in the sedentary series) were defined as any non sedentary period between two sedentary series ${ }^{21}$. Estimates of sedentary time, breaks, and bouts were calculated to represent the pattern of weekly sedentary behavior on weekdays and at week- 
ends (weekdays vs. weekends), as well as during the school (13:30 to 17:50 hours) and non-school periods (remainder of the day monitored by accelerometers). For the purposes of analysis, the sedentary time and accumulated time in bouts were expressed as mean daily values $\left(\mathrm{min}^{\mathrm{day}}{ }^{-1}\right)$ or percentages ( $\%$ of the time of accelerometer use), while breaks were expressed as mean frequency per hour of sedentary time (breaks.hour $\left.{ }^{-1}\right)^{22}$.

To describe the data, descriptive statistics were used with mean values and relative frequency as well as standard deviation and 95\% confidence interval of dispersion. The Kruskal-Wallis, Mann-Whitney and chi-squared tests were used to detect differences between the sexes and socioeconomic status categories. For the comparisons of sedentary patterns of behavior between days of the week and time at school or out of school, the Wilcoxon test for paired samples was used. All analyzes were conducted in the statistical package Stata 14.0, adopting $\mathrm{p}<0.05$.

\section{Results}

In total, 980 adolescents were invited to participate in the study. Refusals and losses totaled 290 individuals (29.5\%), of which 245 were excluded as they did not deliver the informed consent form signed by parents or guardians and 45 because they did not agree to use the accelerometer. Of a total of 690 adolescents who were monitored by accelerometers, 394 presented valid data (57\%) and were included in the analyzes (Table 1). Considering a 95\% confidence level and the estimated standard deviation of the sedentary time of study participants (Table 1), the number of subjects included in the analyzes $(n=394)$ allowed estimates of mean daily sedentary time with a maximum error of 17 minutes. The sample was balanced with regard to sex (female $=52.5 \%$ ), predominantly composed of individuals of economic class B (58.1\%), and about one-third presented excess weight (34.9\%). In general, boys demonstrated greater time in moderate to vigorous physical activity and time of use of the accelerometer $(\mathrm{p}<0.05)$. Approximately 10 hours daily (602 minutes) were spent in sedentary behavior (69.7\% of the time of use of the accelerometers).

The general pattern of sedentary behavior of the sample is shown in Figure 1. Of the total sedentary time recorded in bouts, about 50\% (278 of 535 minutes) was accumulated in short bouts. There was a significant linear decrease in the time recorded in short bouts (1-4 minutes) towards intermediate bouts (1014 minutes), followed by significant increases towards longer bouts ( $\geq 15$ minutes).

Table 1 - Description of the sample according to sex.

\begin{tabular}{llll}
\hline \multicolumn{1}{c}{ Variables } & \multicolumn{1}{c}{$\begin{array}{c}\text { General } \\
(\mathrm{n}=394)\end{array}$} & \multicolumn{1}{c}{$\begin{array}{c}\text { Boys } \\
(\mathrm{n}=187)\end{array}$} & \multicolumn{1}{c}{$\begin{array}{c}\text { Girls } \\
(\mathrm{n}=207)\end{array}$} \\
\hline Age (years) & $11.3 \pm 0.7$ & $11.4 \pm 0.8$ & $11.3 \pm 0.7$ \\
Body mass (kg) & $46.7 \pm 12.5$ & $45.8 \pm 12.3$ & $47.4 \pm 12.8$ \\
Height (cm) & $151.7 \pm 8.1$ & $151.0 \pm 8.7^{*}$ & $152.4 \pm 7.5$ \\
Excess weight (\%) & 34.9 & 35.9 & 34.0 \\
Socioeconomic level (\%) & & & \\
$\quad$ A & 22.6 & 27.4 & 19.7 \\
B & 58.1 & 53.7 & 62.2 \\
C, D and E & 19.3 & 18.9 & 18.1 \\
Use of accelerometer & $854.9 \pm 180.3$ & $872.4 \pm 187.2^{*}$ & $841.2 \pm 173.7$ \\
(min/day) & & & \\
MVPA (min/week) & $519.5 \pm 256.2$ & $597.4 \pm 286.5^{*}$ & $428.6 \pm 200.6$ \\
Sedentary time (min/day) & $602.2 \pm 170.8$ & $611.3 \pm 179.1$ & $593.1 \pm 163.9$ \\
\hline
\end{tabular}

Note. MVPA, moderate to vigorous physical activity. ${ }^{*} \mathrm{p}<0.05$.

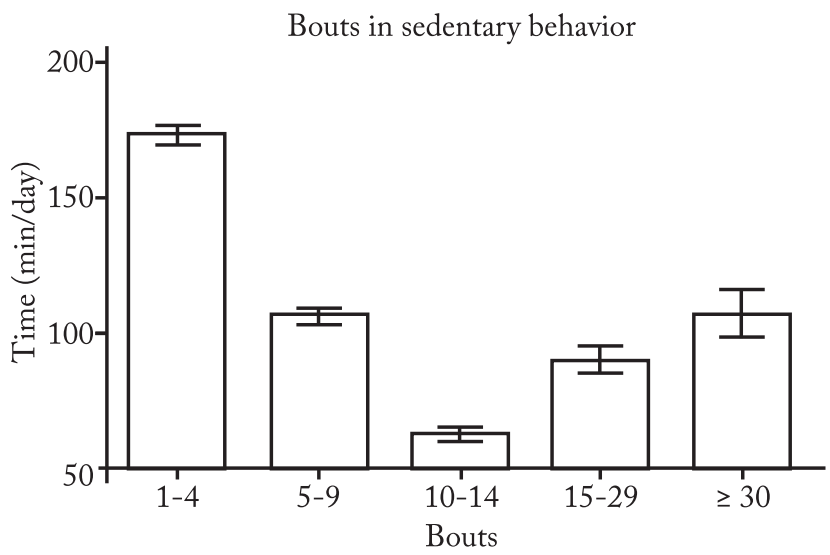

Figure 1 - Pattern of sedentary behavior according to bouts.

Table 2 presents the pattern of sedentary behavior according to sex and socioeconomic level. Boys presented more time in sedentary behavior within the bouts of 5 to 9 minutes than girls. In the other categories of bouts and breaks, no significant differences were found due to sex or economic level. Accumulated time in bouts was similar on weekdays and weekend days (Figure 2). On the other hand, comparisons between bouts revealed that adolescents accumulated more time in short bouts $(<10$ minutes $)$ while in school and more time in longer bouts in out-of-school hours ( $\geq 15$ minutes) ( $<<0.05)$.

Breaks in sedentary behavior according to weekdays and weekends and periods at school or out of school are described in Figure 3. The number of breaks in sedentary behavior per hour was similar between weekdays and weekends. On the other hand, a greater number of breaks was found during the school period ( $p<0.05)$. 
Table 2 - Pattern of sedentary behavior according to sex and socioeconomic level.

\begin{tabular}{lccccc}
\hline \multirow{2}{*}{ Patterns of sedentary behavior } & \multicolumn{2}{c}{ Sex } & \multicolumn{3}{c}{ Socioeconomic level } \\
\cline { 2 - 6 } & $\begin{array}{c}\text { Boys } \\
(\mathrm{n}=187)\end{array}$ & $\begin{array}{c}\text { Girls } \\
(\mathrm{n}=207)\end{array}$ & $\begin{array}{c}\text { A } \\
(\mathrm{n}=83)\end{array}$ & $\begin{array}{c}\text { B } \\
(\mathrm{n}=214)\end{array}$ & $\begin{array}{c}\text { C, D and E } \\
(\mathrm{n}=71)\end{array}$ \\
\hline Sedentary behavior (min/day) & $611.3 \pm 179.1$ & $595.1 \pm 163.9$ & $609.3 \pm 156.4$ & $603.4 \pm 176.1$ & $585.3 \pm 173.6$ \\
Bouts & & & & & \\
1-4 mins (min/day) & $170.9 \pm 37.7$ & $174.7 \pm 32.4$ & $180.0 \pm 38.4$ & $171.2 \pm 34.8$ & $169.1 \pm 34.2$ \\
5-9 mins (min/day) & $109.1 \pm 30.4^{*}$ & $104.1 \pm 24.2$ & $110.2 \pm 27.4$ & $106.5 \pm 27.6$ & $101.1 \pm 27.9$ \\
10-14 mins (min/day) & $64.3 \pm 26.6$ & $61.7 \pm 24.0$ & $65.7 \pm 24.8$ & $63.3 \pm 25.4$ & $57.4 \pm 24.8$ \\
15-29 mins (min/day) & $92.0 \pm 49.6$ & $87.9 \pm 49.8$ & $88.0 \pm 45.3$ & $91.6 \pm 51.7$ & $82.8 \pm 45.6$ \\
$\geq 30$ (min/day) & $113.9 \pm 99.9$ & $101.6 \pm 89.4$ & $101.2 \pm 79.6$ & $108.3 \pm 100.0$ & $111.1 \pm 98.0$ \\
Breaks (breaks/hour) & $11.3 \pm 2.5$ & $11.7 \pm 2.4$ & $11.6 \pm 2.3$ & $11.5 \pm 2.5$ & $11.6 \pm 2.5$ \\
\hline
\end{tabular}

*p $<0.05$.
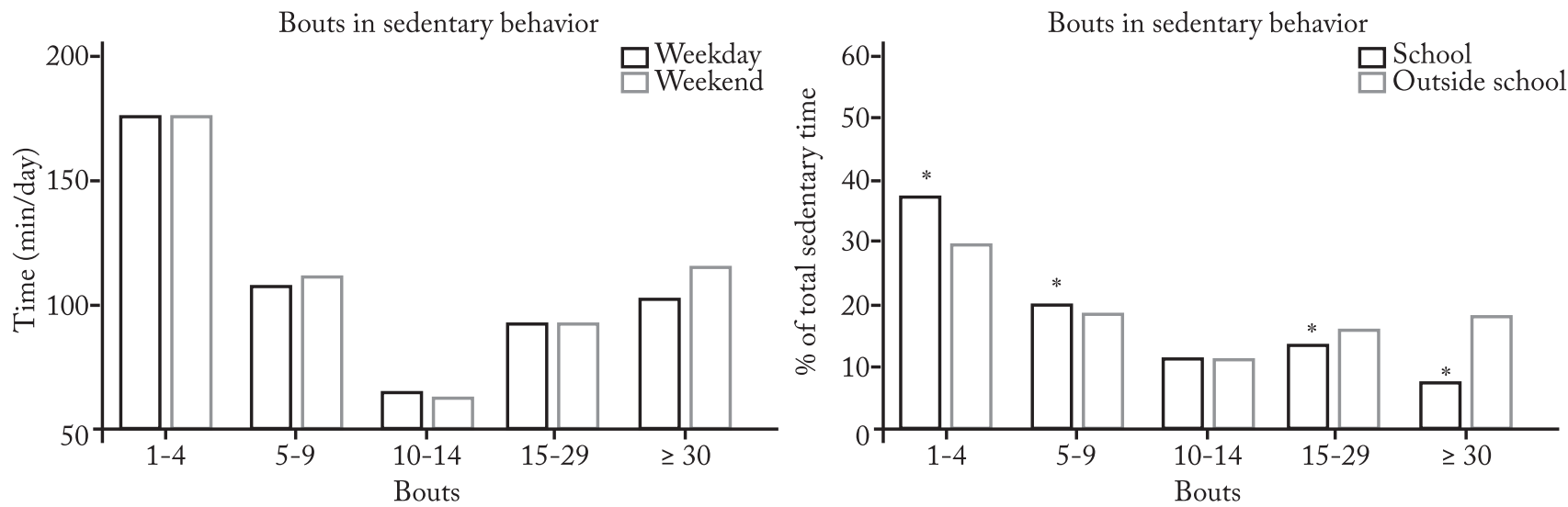

Figure 2 - Pattern of sedentary behavior according to bouts for weekdays or weekends and in or out of school. * $\mathrm{p}<0.05$.
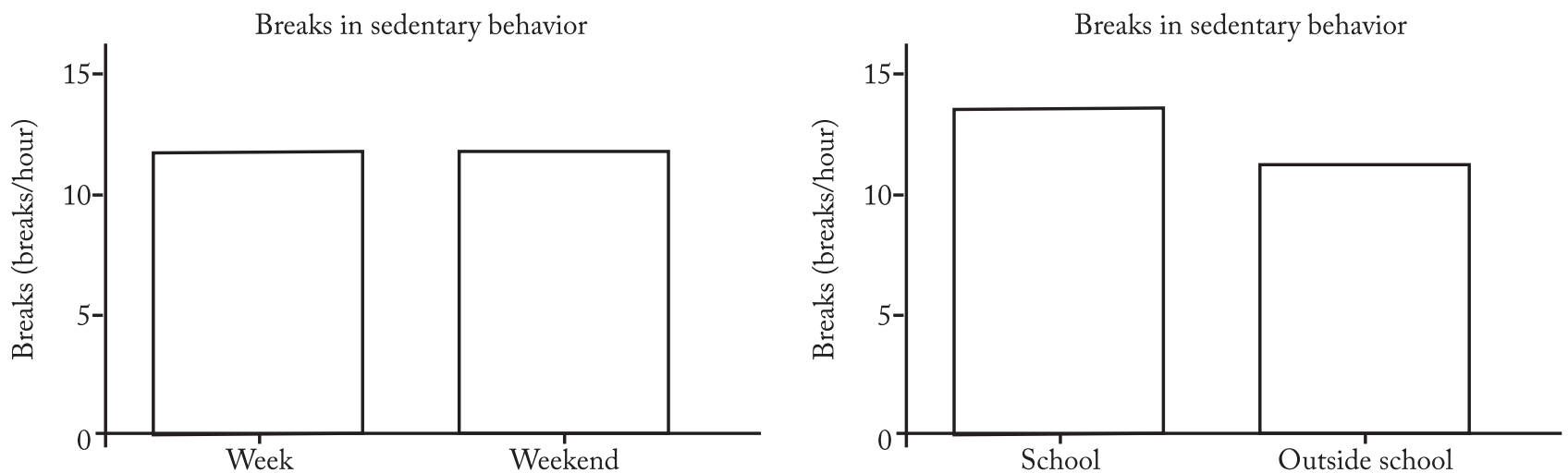

Figure 3 - Pattern of sedentary behavior according to breaks for weekdays or weekends and in or out of school. $* \mathrm{p}<0.05$

\section{Discussion}

The present study found a high volume of sedentary behavior ( 10 hours per day) in Brazilian adolescents, the majority of which ( $>50 \%)$ was accumulated in bouts of short duration $(<10 \mathrm{~min})$. In addition, it was verified that the pattern of sedentary behavior seems to manifest itself similarly on weekdays and at weekends, but differently in the school and non-school environ- ment, in which the accumulation of sedentary time in longer series ( $\geq 15 \mathrm{~min}$ ) was evidenced. Finally, it was observed that the pattern of sedentary behavior appeared not to be influenced by sex or economic level.

The excessive daily time in sedentary activities in the students of the present study is at least similar to those observed in adolescents from developed countries ${ }^{5,9,23}$. Direct comparisons between the studies regarding the 
time spent in sedentary behavior (minutes or hours per day) are inadequate due to differences between studies in terms of the time of use of accelerometers and cut-off points used to characterize sedentary activities. However, when analyzing the percentage of sedentary time according to the use of accelerometers, the results of the present study revealed that Brazilian adolescents present one of the highest rates of sedentary behavior $(69.7 \%$ of the time of use), although lower than that observed in Canadian adolescents (71.3\% of the time of use $)^{23}$.

The high sedentary time in the sample of the present study was mostly accumulated through bouts of short duration $(<10 \mathrm{~min}$ ), which corroborates with previous studies ${ }^{9,23}$. However, findings from this research revealed that Brazilian adolescents accumulate, on average, three times the sedentary time in prolonged bouts ( $\geq 30 \mathrm{~min}$ ) when compared to adolescents from developed countries ${ }^{9,23}$. In these studies, the time accumulated in sedentary bouts decreased linearly from the shortest to the longest bouts, while in our sample the decrease was observed until intermediate bouts (10-14 $\mathrm{min})$, after which there were important increases. This fact is of concern, since prolonged periods of uninterrupted sedentary behavior tend to impair the uptake of fatty acids derived from lipoproteins due to an inhibition of lipoprotein lipase activation, which may lead to the onset of risk factors for cardiometabolic diseases ${ }^{24}$.

This greater accumulation of sedentary time in prolonged bouts reflects a pattern of sedentary behavior differentiated between the school and non-school environments. Differently from previous findings ${ }^{13}$, we identified that adolescents from this sample accumulated more time in prolonged bouts of sedentary behavior during out-of-school time and, consequently, a greater number of breaks from sedentary behavior during the school period. This inconsistency may reflect, at least in part, differences in the school environment (full-time versus part-time) between the countries of both studies, as well as cultural differences between European and Brazilian adolescents (which may lead to differentiated behaviors in the school environment). As full-time education is not a reality of the sample investigated, the adolescents may be exposed to a greater amount of free time for excessive and unsupervised use of technology (cell phones, video games, TV) in the domestic environment, supposedly leading to a greater accumulation of time in sedentary bouts. However, these facts cannot be confirmed in the present study.

This more unfavorable pattern of sedentary behav- ior (greater presence of prolonged bouts and fewer breaks) in the non-school environment was an interesting finding of the present study. In this sense, even if a large part of current interventions aimed at reducing and/or disrupting adolescent sedentary behavior are school-based, such as the use of height adjustment tables $^{25}$, these findings lead to the recommendation that future interventions should also emphasize the period outside school, such as the use of measures to reduce screen time or even family interventions ${ }^{26}$.

The high sample loss, due to a low rate of individuals with valid accelerometer data (57\%), is one of the main limiting factors of the study. However, subjects who were excluded from the study and/or analyzes presented a similar distribution to the sample investigated with respect to sex, socioeconomic level, and mean age. Thus, considering that the pattern of sedentary behavior was not dependent on sex or socioeconomic level, we believe that little bias was introduced in the study estimates. In addition, it is important to highlight that the study was limited to investigating adolescents in a restricted age range of public schools, which presupposes some caution regarding the generalization of the results. Finally, a triaxial cut-off point for ActiGraph was adopted, which, despite being derived from a study involving Brazilian adolescents, differs from the traditional cut-off point used in the literature ${ }^{27}$. In this sense, when analyzing the sedentary time using the cut-off point of 100 counts. $\mathrm{min}^{-1}$ for the vertical axis of the ActiGraph, the sedentary time estimates were extremely similar to those presented in the present study (604.9 versus 602.2 min.day 1). Some highlights of the study also deserve attention. The average time of use of the accelerometers was high ( 14 hours), guaranteeing an approximate coverage of about $90 \%$ of the awake time of the adolescents. It is also highlighted that this is one of the first studies to characterize the pattern of sedentary behavior in Brazilian adolescents through the use of objective measures. Thus, the data presented herein allow better understanding of the way sedentary behavior is manifested in different contexts of adolescent life, supporting future interventions, or even providing a baseline for monitoring trends.

In conclusion, Brazilian adolescents present high levels of sedentary time (about 10 hours per day), characterized by a less favorable pattern (prolonged bouts and shorter occurrences of breaks) in the period when they are outside the school environment. Sex, economic status, and period of the week (weekdays and weekends) do not seem to influence the pattern of sedentary behavior among adolescents. 


\section{Conflict of interest}

The authors declare no conflict of interests.

\section{Authors' contributions}

Ramos DE, Bueno MRO, Zambrin LF and Werneck AO participated in the design of the project; collection, analysis and interpretation of the data; writing of the initial version of the manuscript. Ronque ERV, Coelho-E-Silva MJ and Romanzini $M$ participated in project design; analysis of interpretations of data; critical review of the manuscript. All authors approved the final version of the manuscript.

\section{References}

1. Network SBR. Letter to the editor: Starndardized use of the terms "sedentary" and "sedentary behaviors." Appl Physiol Nutr Metab. 2012;37:540-2.

2. Saunders TJ, Chaput JP, Tremblay MS. Sedentary behaviour as an emerging risk factor for cardiometabolic diseases in children and youth. Can J Diabetes. 2014;38(1):53-61.

3. Tremblay MS, Aubert S, Barnes JD, Saunders TJ, Carson V, Latimer-Cheung AE, et al. Sedentary behavior research network (SBRN) - Terminology consensus project process and outcome. Int J BehavNutr Phys Act. 2017;14:75.

4. Cliff DP, Jones RA, Burrows TL, Morgan PJ, Collins CE, Baur LA, et al. Volumes and bouts of sedentary behavior and physical activity: Associations with cardiometabolic health in obese children. Obesity. 2014;22(5):112-8.

5. Júdice PB, Silva AM, Berria J, Petroski EL, Ekelund U, Sardinha LB. Sedentary patterns, physical activity and health-related physical fitness in youth: a cross-sectional study. Int J BehavNutr Phys Act. 2017;14(1):25.

6. Saunders TJ, Tremblay MS, Mathieu MĖ, Henderson M, O'Loughlin J, Tremblay A, et al. Associations of sedentary behavior, sedentary bouts and breaks in sedentary time with cardiometabolic risk in children with a family history of obesity. PLoS One. 2013;8(11).

7. Cliff DP, Hesketh KD, Vella SA, Hinkley T, Tsiros $\mathrm{MD}$, Ridgers ND, et al. Objectively measured sedentary behaviour and health and development in children and adolescents: Systematic review and meta-analysis. Obes Rev. 2016;17(4):330-44.

8. Australian Goverment DH. Australia's Physical Activity and Sedentary Behaviour Guidelines for Children. url:http:// www.health.gov.au/ internet/main/publishing.nsf/content/ health-pubhlth-strategphys-act-guidelines\#apa512. 2017.

9. Verloigne M, Ridgers ND, Chinapaw M, Altenburg TM, Bere E, Van Lippevelde W, et al. Patterns of objectively measured sedentary time in 10- to 12-year-old Belgian children: an observational study within the ENERGYproject. BMC Pediatr. 2017;17(1):147.

10. Carson V, Cliff DP, Janssen X, Okely AD. Longitudinal levels and bouts of sedentary time among adolescent girls. BMC Pediatr. 2013;13(1):173.

11. Guerra PH, Farias Júnior JC de, Florindo AA. Sedentary behavior in Brazilian children and adolescents: a systematic review. Rev Saude Publica. 2016;50:1-15.
12. Costa BGG, Silva KS, George AM, Assis MAA. Sedentary behavior during school-time: Sociodemographic, weight status, physical education class, and school performance correlates in Brazilian schoolchildren. J Sci Med Sport. 2017;20(1):70-4.

13. Abbott RA, Straker LM, Mathiassen SE. Patterning of children's sedentary time at and away from school. Obesity. 2013;21(1):2012-4.

14. Harrington DM, Dowd KP, Bourke AK, Donnelly AE. Cross-Sectional analysis of levels and patterns of objectively measured sedentary time in adolescent females. Int J Behav Nutr Phys Act. 2011;8(1):120.

15. Steele RM, van Sluijs EM, Sharp SJ, Landsbaugh JR, Ekelund U, Griffin SJ. An investigation of patterns of children's sedentary and vigorous physical activity throughout the week. Int J BehavNutr Phys Act. 2010;7(1):88.

16. Gordon CC. Stature, recumbent length, and weight. In: Anthropometric standardization reference manual.1988.p.3-8.

17. Cole TJ, Lobstein T. Extended international (IOTF) body mass index cut-offs for thinness, overweight and obesity. Pediatr Obes. 2012;7(4):284-94.

18. ABEP- Associação Brasiliera de Empresas de Pesquisa. Critérios de Classificação Econômica Brasil.São Paulo: 2015. Disponível em: http://www.abep.org/criterio-brasil. 2015.

19. Kim Y,LeeJM,Peters BP, Gaesser GA,Welk GJ.Examination of different accelerometer cut-points for assessing sedentary behaviors in children. PLoS One. 2014;9(4):1-8.

20. Romanzini M, Petroski EL, Ohara D, Dourado AC, Reichert FF. Calibration of ActiGraph GT3X, Actical and RT3 accelerometers in adolescents. Eur J Sport Sci. 2014;14(1):91-9.

21. Altenburg TM, Chinapaw MJM. Bouts and breaks in children's sedentary time: Currently used operational definitions and recommendations for future research. Prev Med. 2015;77:1-3.

22. Healy G, Dunstan DW, Salmon J, Cerin E, Shaw J, Zimmet $\mathrm{P}$, et al. Beneficial associations with metabolic risk. Diabetes Care. 2008;31(4):661-6.

23. Carson V, Stone M, Faulkner G. Patterns of Sedentary Behavior and Weight Status among Children. Pediatr Exerc Sci. 2014;26(1):95-102.

24. Marc T Hamilton, Deborah G Hamilton TWZ. NIH Public Access. Exerc Sport SciRev. 2004;32(4):161-6.

25. Minges KE, Chao AM, Irwin ML, Owen N, Park C, Whittemore R, et al. Classroom Standing Desks and Sedentary Behavior: A Systematic Review. Pediatrics. 2016;137(2):e20153087-e20153087.

26. Altenburg TM, Kist-van Holthe J, Chinapaw MJM. Effectiveness of intervention strategies exclusively targeting reductions in children's sedentary time: a systematic review of the literature. Int J BehavNutr Phys Act. 2016;13(1):65.

27. Evenson KR, Catellier DJ, Gill K, Ondrak KS, McMurray RG. Calibration of two objective measures of physical activity for children. J Sports Sci. 2008;26(14):1557-65.

Recebido: $14 / 07 / 2017$

Aprovado: 18/09/2017 